\title{
Atrial fibrillation and what else?
}

\author{
S. M. van den Bogaard · F. E. Vervaat - P. H. van der Voort
}

Accepted: 20 January 2022 / Published online: 25 February 2022

(C) The Author(s) 2022

\section{Answer}

Initially, the bursts of wide complex tachycardia were diagnosed as non-sustained ventricular tachycardia (VT); however, higher doses of beta blocker increased the occurrence of wide complex tachycardia, without affecting the heart rate in atrial fibrillation (AF). The respiratory condition of the patient deteriorated further during the hospital stay, necessitating transfer to the intensive care unit, intubation and initiation of mechanical ventilation. To optimise the haemodynamic state, transoesophageal echocardiographyguided electrical cardioversion was performed after left atrial appendage thrombosis had been excluded. The electrical cardioversion was successful with restoration of sinus rhythm (Fig. 1).

The electrocardiogram during sinus rhythm now revealed ventricular pre-excitation over a left-sided accessory pathway (AP). The patient's first electrocardiogram (see Fig. la in the Question) had shown AF with exclusively narrow QRS complexes; antegrade conduction over the AP was concealed by retrograde (partial) conduction in the AP. Beta blockers slowed the conduction in the AV node, decreasing retrograde concealment and facilitating antegrade conduction over the AP (see Fig. $1 b$ in the Question) [1].

Beta blockers have been shown to increase ventricular rate [2]. Potential mechanisms include (1) direct shortening of the AP refractory period, which is unlikely [3], (2) indirect shortening of the refractory period by catecholamines and (3) decreased concealed conduction [2]. In the current guidelines, beta blockers are contra-indicated in patients with pre-excita- tion and AF for this reason. After cardioversion, the patient remained in sinus rhythm, but he died from pulmonary complications of COVID-19.

Conflict of interest S.M. van den Bogaard, F.E. Vervaat and P.H. van der Voort declare that they have no competing interests.

Open Access This article is licensed under a Creative Commons Attribution 4.0 International License, which permits use, sharing, adaptation, distribution and reproduction in any medium or format, as long as you give appropriate credit to the original author(s) and the source, provide a link to the Creative Commons licence, and indicate if changes were made. The images or other third party material in this article are included in the article's Creative Commons licence, unless indicated otherwise in a credit line to the material. If material is not included in the article's Creative Commons licence and your intended use is not permitted by statutory regulation or exceeds the permitted use, you will need to obtain permission directly from the copyright holder. To view a copy of this licence, visit http://creativecommons.org/licenses/by/4.0/.

\section{References}

1. Klein GJ, Yee R. Sharma AD Concealed conduction in accessory atrioventricular pathways: an important determinant of the expression of arrhythmias in patients with WolffParkinson-White syndrome. Circulation. 1984;70:402-11.

2. Morady F, Dicarlo LA, Baerman JM, de Buitleir M. Effect of propranolol on ventricular rate during atrial fibrillation in the Wolff-Parkinson-White syndrome. Pacing Clin Electrophysiol. 1987;10(3 Pt 1):492-6.

3. Denes P, Cummings JM, Simpson R, et al. Effects of propanolol on anomalous pathway refractoriness and circus movement tachycardias in patients with preexcitation. AmJ Cardiol. 1978;41:1061-7. 


\section{Rhythm Puzzle - Answer}

Fig. 1 ECG after electrical cardioversion showing sinus rhythm with ventricular pre-excitation. ECG electrocardiogram

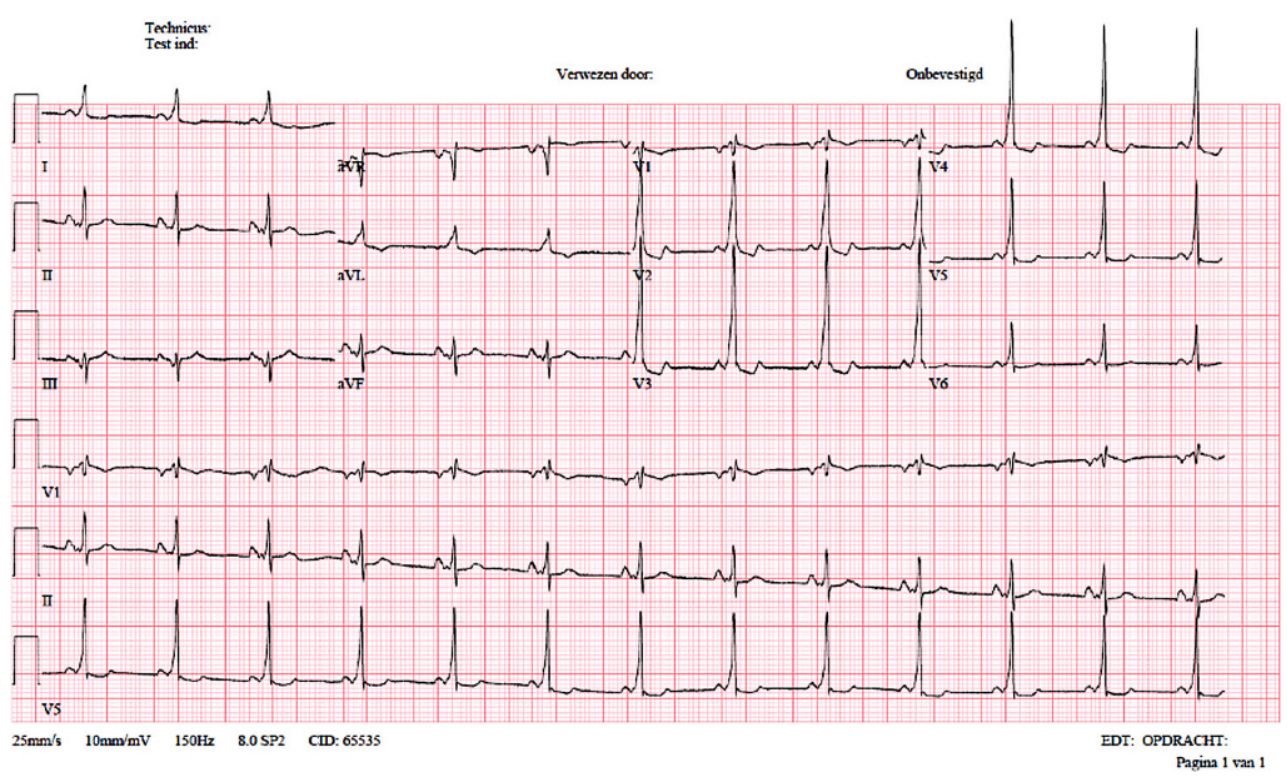




\title{
Advertisement placed here.
}

\author{
ces bohn \\ LL $\begin{aligned} & \text { stafleu } \\ & \text { van loghum }\end{aligned}$ \\ Springer Media
}

Houten 2021 


\title{
Advertisement placed here.
}

\author{
ces bohn \\ LL $\begin{aligned} & \text { stafleu } \\ & \text { van loghum }\end{aligned}$ \\ Springer Media
}

Houten 2021 